\title{
Madelung Deformity: Diagnosis and Treatment Options
}

\section{Deformidad de Madelung: opciones de diagnóstico y tratamiento}

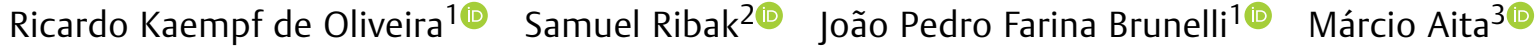 \\ Pedro J. Delgado4(1)
}

${ }^{1}$ Department of Hand Surgery, Santa Casa de Misericórdia, Porto

Alegre, Brazil

${ }^{2}$ Department of Hand Surgery, Pontifícia Universidade Católica de


Leopoldo Bier 825/301, Porto Alegre, 90620-100, Rio Grande do Sul, Campinas, Campinas, Brazil

${ }^{3}$ Department of Hand Surgery, Faculdade de Medicina do ABC, Santo André, Brazil

${ }^{4}$ Department of Hand and Upper Limb Surgery, Hospital Universitário HM Montepríncipe, Universidad CEU San Pablo, Boadilla del Monte, Madrid, Spain

Rev Iberam Cir Mano 2021;49(2):e140-e154.

\begin{abstract}
Keywords

- Madelung deformity

- longitudinal dysplasia

- wrist subluxation

- congenital hand anomalies

- historical perspective
\end{abstract}

Madelung deformity (MD) comprises an increased volar and ulnar tilt of the joint facet of the distal radius, secondary to an idiopathic physeal dysplasia. Such change causes radial shortening and consequent distal ulnar prominence, along with wrist pain and loss of motion. Surgery becomes an option in patients with severe deformity that do not respond to conservative treatment.

The classic surgical techniques are problematic for adults, as they are specific for children and adolescents, whose radial physis is still open. Very few papers discuss the treatment of adult patients; furthermore, most are focused on the distal radioulnar joint, and thus do not approach the origin of the pathology.

When analyzing computed tomography scans with tridimensional reconstruction, a feature of MD, growth arrest of the volar and ulnar portions of the distal radius, is noted, causing the typical distal radius deformity that leads to lack of coverage of the lunate bone. That leads to palmar subluxation of the lunate bone and consequent radiocarpal instability.

We herein describe the possibilities of treatment in different stages of evolution, summarizing the authors' view on MD. received

July 20, 2021

accepted after revision

October 1, 2021
DOI https://doi.org/ $10.1055 / \mathrm{s}-0041-1739452$ ISSN 1698-8396.

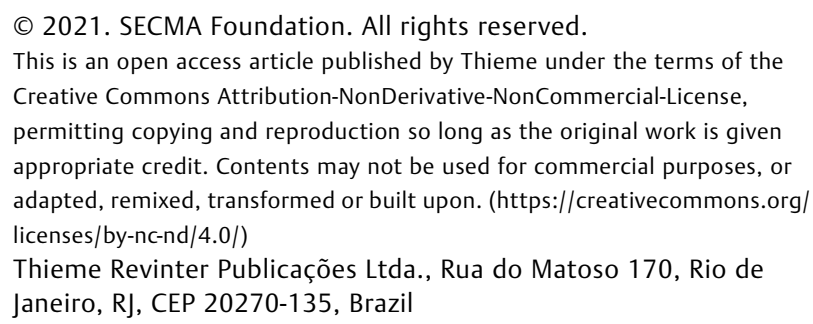
Creative Commons Attribution-NonDerivative-NonCommercial-License, permitting copying and reproduction so long as the original work is given appropriate credit. Contents may not be used for commercial purposes, or adapted, remixed, transformed or built upon. (https://creativecommons.org/ licenses/by-nc-nd/4.0/) Thieme Revinter Publicações Ltda., Rua do Matoso 170, Rio de Janeiro, RJ, CEP 20270-135, Brazil 


\section{Resumen}

Palabras clave

- deformidad de Madelung

- displasia longitudinal

- subluxación de muñeca

- malformaciones congénitas de la mano

- perspectiva histórica
La deformidad de Madelung (DM) comprende un aumento de la inclinación volar y cubital de la faceta articular del radio distal, secundaria a una displasia fisaria idiopática. Tal cambio causa un acortamiento radial y la consecuente prominencia cubital distal, junto con dolor en la muñeca y pérdida de movimiento. La cirugía se convierte en una opción en pacientes con deformidad severa que no responden al tratamiento conservador.

Las técnicas quirúrgicas clásicas son problemáticas para los adultos, pues son específicas para niños y adolescentes, cuya fisis radial aún está abierta. Muy pocos artículos discuten el tratamiento de pacientes adultos; además, la mayoría se centra en la articulación radiocubital distal y, por tanto, no se acercan al origen de la patología. Al analizar la tomografía computarizada con reconstrucción tridimensional, se observa una característica de la DM, la detención del crecimiento de las porciones volar y cubital del radio distal, lo que provoca la deformidad típica del radio distal que conduce a la falta de cobertura del hueso semilunar. Eso conduce a una subluxación palmar del hueso semilunar y la consiguiente inestabilidad radiocarpiana.

Decribimos en este artículo las posibilidades de tratamiento en distintas etapas de evolución, y resumimos las opiniones de los autores sobre la DM.

\section{History}

Madelung deformity (MD) consists of a complex of wrist deformities originating from the asymmetrical physeal involvement of the distal radius that affects both the volar and ulnar regions, an area corresponding to the lunate fossa. It is an autosomal dominant disorder with incomplete penetrance in $40 \%$ of the cases, and has also been referred to as dyschondroplasia, osteochondrodystrophy, or hemiatrophy of the distal physis. ${ }^{1-5}$

Otto Madelung (-Fig. 1A) was a German surgeon who detailed the deformity and its treatment in 1878 . Nonetheless other authors, including those cited by Madelung, had described the pathology earlier, such asDupuytren (1834), Smith (1847), Adams (1854), Malgaigne (1855), and Jean $(1875) .^{2-6}$

The term Madelung deformity differs from Madelung disease, which is employed to denote another disease that was described by the same surgeon: benign lipomatosis of the cervical region (-Figs. $\mathbf{1 B}$ and $\mathbf{1 C})^{2}$

Today, we already know many aspects of MD; nonetheless, its cause remains unknown. The deformity occurs due to a failure in growth and development of the ulnar and volar regions of the distal portion of the radius. It is classically attributed to an early physeal closure, and the disease is also called dyschondrosteosis ${ }^{1,2,5,7-9}$.

In 1992 , Vickers and Nielsen ${ }^{10}$ published a series of cases of 17 patients with MD, and described an anatomical change in the volar radiocarpal ligaments directed to the lunate bone. They described those changes as a thick tether, and the increased tension upon those ligaments over the physis of that area of the radius would be the cause of its growth arrest. Unlike the normal ligament, this originates from the metaphysis, crosses the physis and, according to the most accepted theory, inflicts physeal compression during growth. This structure would be later known as Vickers ligament ${ }^{1,4}$.
Carter and Ezaki ${ }^{13}$ confirmed its existence in $91 \%$ of cases operated for MD. This anomalous ligament is a matter of discussion, and may be considered the cause of the changes in both the lunate bone and carpus, or it may represent compensatory hypertrophy of the radiocarpal capsule and radiolunate ligament shortening secondary to bone deformity. ${ }^{11,12}$ The tendency of the lunate bone toward proximal and volar migration due to the dysplastic aspect of the radial fossa would then culminate in its hypertrophy. Prior to the description by Vickers and Nielsen, ${ }^{10}$ Linscheid had already described anatomical changes in the volar radiocarpal ligaments and the pronator quadratus muscle in patients with MD.

The radius becomes shortened and distally deviated towards volar and ulnar directions due to the growth deficit in the anteromedial portion of the distal physis. Those anatomical changes cause the distal ulna to become prominent, as there is no growth arrest in this bone. With volar subluxation of the carpus, these features give rise to a bayonet-shaped deformity (-Fig. 2). ${ }^{1,4,5}$

It is important to highlight that some deformities may simulate MD (known as pseudo-Madelung), such as multiple osteochondromatosis; "gymnast's fist"; posttraumatic physeal injuries; rickets; and inflammatory or infectious arthritis, which are usually unilateral lesions. ${ }^{1,13}$

A deformity called reverse MD has also been described in the literature, in which the growth disturbance at the ulnar portion of the distal radial epiphysis is located dorsally, instead of volarly, leading to the anterior tilt of the ulna and dorsal deviation of the hand due to a reverse radial arch. ${ }^{14}$

\section{Epidemiology}

Corresponding to only $1.7 \%$ of congenital hand and upper limb deformities, MD is rare. There is a female-to-male ratio of $4: 1$, and bilaterality in $\sim 74 \%$ of the cases. ${ }^{1,4,5,13}$ 




Fig. 1 German surgeon Otto W. Madelung (1846-1926) (A), author of the description of MD, which is an increased volar and ulnar tilt of the joint facet of the distal radius, secondary to an idiopathic physeal dysplasia (B). He is also, the author of the description of Madelung disease, which is the benign lipomatosis of the cervical region (C). (Modified from J Hand Surg Am, 2006;31:177-182 ${ }^{2}$ ).

Most cases occur in isolation, and patterns of genetic inheritance have already been associated with this form of presentation. There is also a strong association of this pathology with Leri-Weil dyschondrosteosis, a skeletal dysplasia associated to haploinsufficiency of the SHOX gene. This gene is located at the pseudoautosomal region of the $\mathrm{X}$ and $\mathrm{Y}$ chromosomes, representing a transmission pattern that differs from that of the sex-linked genetic pathologies (pseudoautosomal pattern). Thus, the chance that children from carriers of SHOX haploinsufficiency disorders will inherit the genetic defect is of $50 \%$. There is also an association to other diseases that change the structure of the SHOX gene, which evolves with the development of MD, such as Turner syndrome. Furthermore, there are some patterns of genetic defects that independently originate the pathology, such as the GNAS mutation. The field of genetics is increasingly advanced on the understanding of the causation. $2,7,13,15$

\section{Diagnosis}

\section{Clinical Aspects}

It is known that MD develops years before causing any clinically-relevant tilts or symptoms. The hypoplastic growth of the distal portion of the radius (volar and ulnar regions) ends up with a multitude of structural changes, most notably increased palmar and ulnar tilt of the distal radius; anterior curvature of the radial diaphysis; flattening or the absence of the ulnar physis of the distal radius; dorsal prominence of the ulnar head; increased distal ulnar tilt; and proximal migration of the lunate bone, leading to an inverted pyramid-shaped or inverted triangle carpal appearance on the $\mathrm{X}$-rays. Subtle changes may be detected during childhood if there is a high level of suspicion. However, the signs of the disease become apparent in early adolescence, during the phase of rapid bone growth. The symptoms include pain and cosmetic complaints in addition to varied levels of loss of range of motion (ROM) of the wrist, especially on supination and extension. $2,4,7,10$

Clinically, the patient presents with complaints related to a long (relative length) and dorsally-subluxated ulna due to radial shortening. The hand may assume a more anterior and ulnar position in relation to the wrist due to carpal migration; however, the first manifestations noticed by the patient are generally related to the ulna. There may also be complaints that the affected limb is shorter when the deformity is unilateral. Skeletal changes have also been reported in 


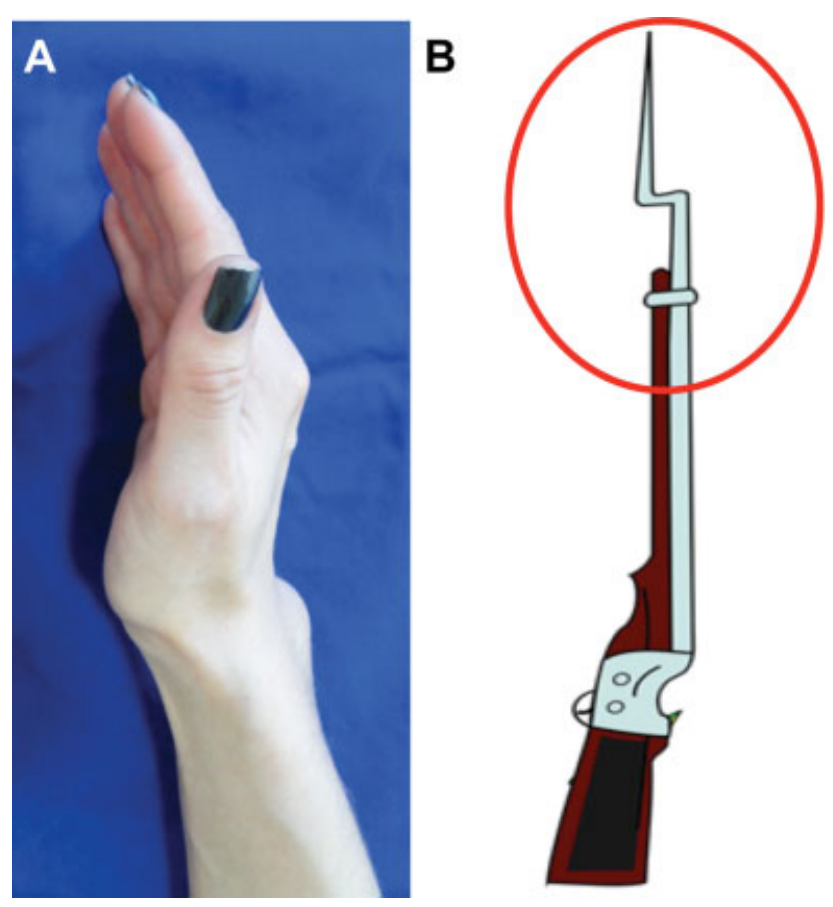

Fig. 2 Due to the asymmetric growth of the distal physis of the radius, MD features an association of anatomical variations. The radius becomes shortened and its distal aspect tilts volarly and ulnarly. Those anatomical changes cause the distal ulna to become prominent as there is no growth arrest in this region. With volar subluxation of the carpus, these features give rise to a bayonet-shaped deformity $(A, B)$.

patients with MD, such as cubitus valgus, tibial bowing, absence of the humeral head, shortened arms and legs, and brachydactyly. Many of them occur in patients with dyschondrosteosis. ${ }^{1,11}$

\section{Radiography}

The main imaging modality for MD is radiography. Posteroanterior and lateral images provide the information on most of the structural changes in the wrist. ${ }^{1,16,17}$ The carpus appears as an inverted pyramid or triangle, with the apex toward the lunate bone; there is an increase in the relative length of the ulna; and ulnar dorsal subluxation with distal radioulnar joint (DRUJ) opening may also be observed, along with widening and distortion of the normal anatomy of the ulnar head. Increased ulnar and palmar tilts of the radius are identified, and the fossa from the medial metaphysis of the radius becomes flame-shaped at the insertion site of the Vickers ligament. The carpus remains subluxated volarly and ulnarly, and, due to flattening of the ulnar physis of the distal radius, bowing of the anterior diaphysis of the radius ensues. $^{16-20}$

The surface of the radial joint shows an average ulnar deviation of $60^{\circ}$ on the anteroposterior view (normal values: $\sim 23^{\circ}$ ), and a volar tilt of $35^{\circ}$ on the lateral view (normal value: $11^{\circ}$ ). The angle between the radius and the third metacarpal bone, usually of $5^{\circ}$, is greater than $15^{\circ}$ in MD. ${ }^{16-21}$

The aforementioned changes, when identified in isolation, do not warrant the diagnosis and, therefore, McCarroll

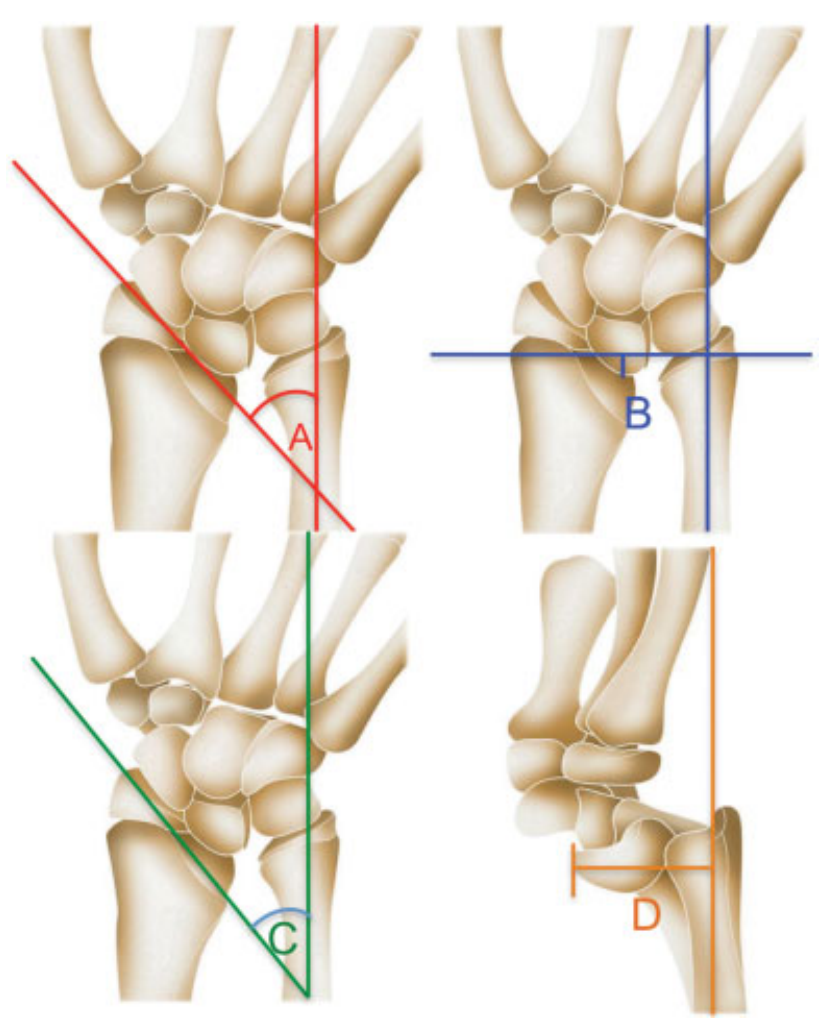

Fig. 3 Radiographic patterns that McCarroll et al. ${ }^{16}$ have determined for the diagnosis of MD. Anteroposterior radiograph: ulnar tilt (A); lunate sinking (B); and angle of the lunate fossa (C). Lateral radiograph: volar carpal displacement (D).

et al. ${ }^{16}$ have established radiographic patterns that, when added together, provide a high positive predictive value for the diagnosis of MD (-Fig. $\mathbf{3}$ ).

\section{Radiographs on Anteroposterior View}

- Ulnar tilt: the complement of acute angle A (90-A), which is formed by a line corresponding to the ulnar longitudinal axis and another line tangential to the proximal surface of the scaphoid and lunate bones; MD is characterized whenever the angle exceeds $33^{\circ}$.

- Sinking of the lunate bone: distance in millimeters from a line perpendicular to the longitudinal axis of the ulna, at the join line, and the most proximal point of the lunate bone. It is positive if the ulna goes beyond that point, and MD is characterized if it exceeds $4 \mathrm{~mm}$.

- Angle of the fossa of the lunate bone: the complement of acute angle $C(90-C)$, which is formed by the longitudinal axis of the ulna and a tangential line toward the fossa of the lunate bone; MD is characterized if the angle is greater than $40^{\circ}$.

\section{Radiographs on Lateral View}

- Volar carpal displacement: distance in millimeters between the longitudinal axis of the ulna and the most palmar point at the surface of the lunate or capitate bones; MD is characterized if it exceeds $20 \mathrm{~mm}$. 


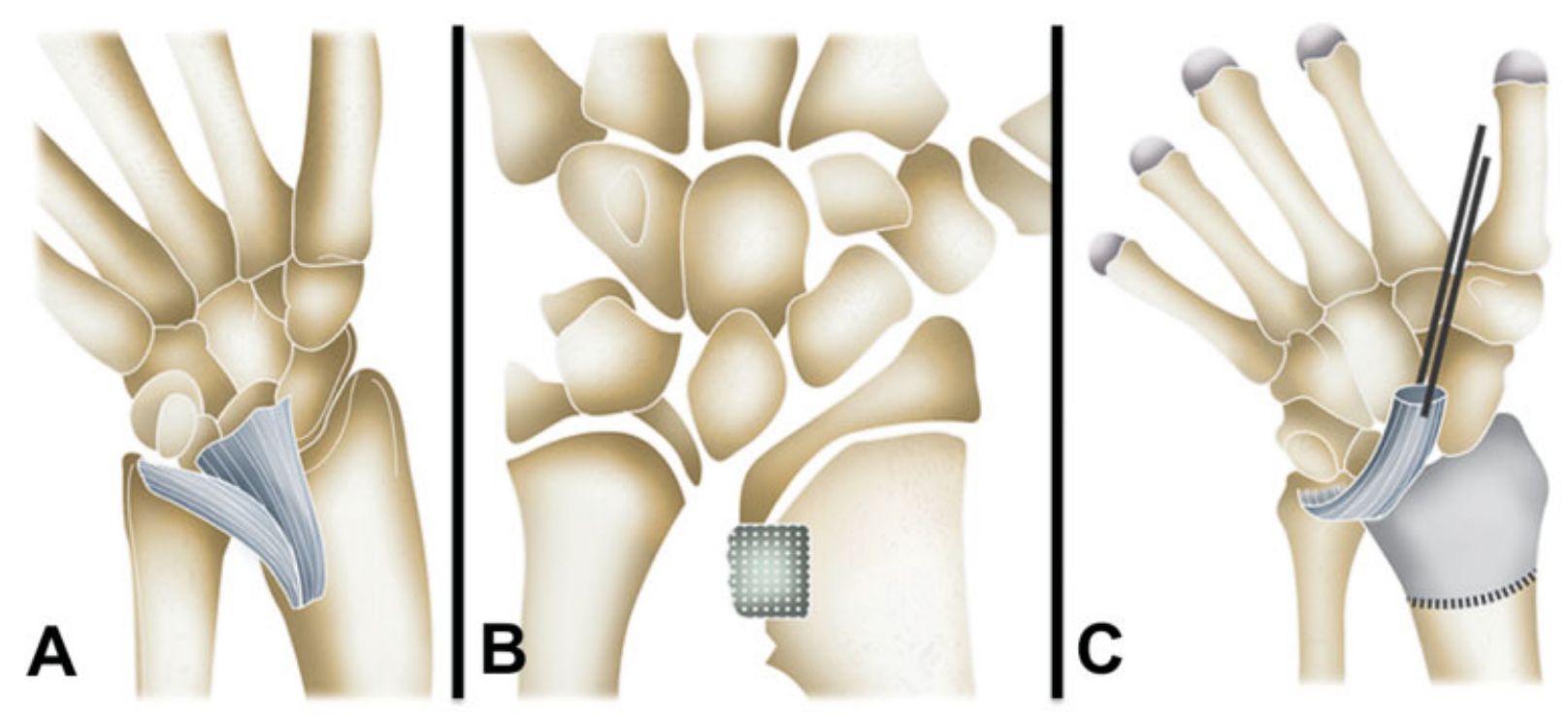

Fig. 4 Detail of the Vickers ligament, which is an anatomical change in the volar radiocarpal ligaments toward the lunate. It consists of a thick cord that theoretically increases the tension on the physis of the distal radius (A). Langenskiöld procedure for young patients with high growth potential, consisting of release of the physeal bar (epiphysiolysis) and fat interposition within the void created (B). Dome-shaped metaphyseal distal radius osteotomy associated with resection of the Vickers ligament, indicated for adolescent patients with deformity and no degenerative changes (C).

\section{Magnetic Resonance Imaging}

Magnetic Resonance Imaging (MRI) is not necessary for the diagnosis, but it may contribute for a better tridimensional understanding of the deformity, and it also shows the presence of the Vickers ligament, and enables the assessment of secondary changes in the triangular fibrocartilage complex, and the determination of the extent of physeal compromise. ${ }^{1,3,21}$ Some authors advocate that MRI in children with a family history of the disease may show early evidence of thickening of the volar radiocarpal ligament and provide an earlier treatment with resection, thus avoiding disease progression. In their classic article, Vickers and Nielsen ${ }^{10}$ advocated the use of MRI for the early diagnosis to identify the presence of the anomalous ligament, but such indication is not a consensus ${ }^{22-24}$ (-Fig. 4A, 4B, 4C).

Another possible indication for MRI in cases of MD would be to assess the growth potential of the physis of the distal radius, as well as to plan a possible release, or for the diagnosis of secondary degenerative processes in case of salvage surgical procedures. ${ }^{25-27}$

\section{Computed Tomography}

Computed tomography (CT) is also useful for the surgical planning, especially in cases of distal radius osteotomies and DRUJ adjustments. ${ }^{28,29}$

\section{Treatment}

\section{Non-surgical Treatment}

Little is known about the natural history of MD. Some patients remain knowingly either asymptomatic or with few complaints even into adulthood. Nonetheless, some patients present progressive symptoms due to the degenerative process of the DRUJ, with or without instability, radiocarpal arthrosis, and ulnocarpal impingement. At present, with the current data, it is almost impossible to predict which patients will be symptomatic., ${ }^{1,3,21}$

Asymptomatic patients with no severe deformities or significant chondral compromise, and without cosmetic complaints, are to be followed up every six months until adulthood $^{21}$ (- Fig. 5).

For patients with few synmptoms and mild deformity, non-surgical treatment is the consensus. For these cases, symptom relief is achieved with referentiation to a hand therapist, use of orthoses, systemic and local anti-inflammatory drugs, and application of ice packs ${ }^{1}$ (-Fig. 6).
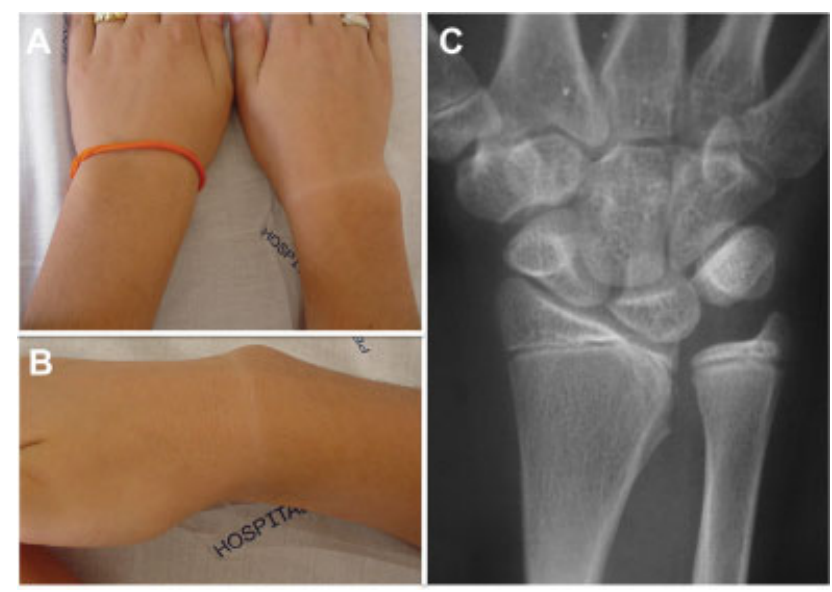

Fig. 5 Female patient, 10 years old, with bilateral MD, more pronounced on the left $(A, B)$. The patient had few symptoms; the main finding was loss of supination. Radiography reveals the main features of the disease (C). 


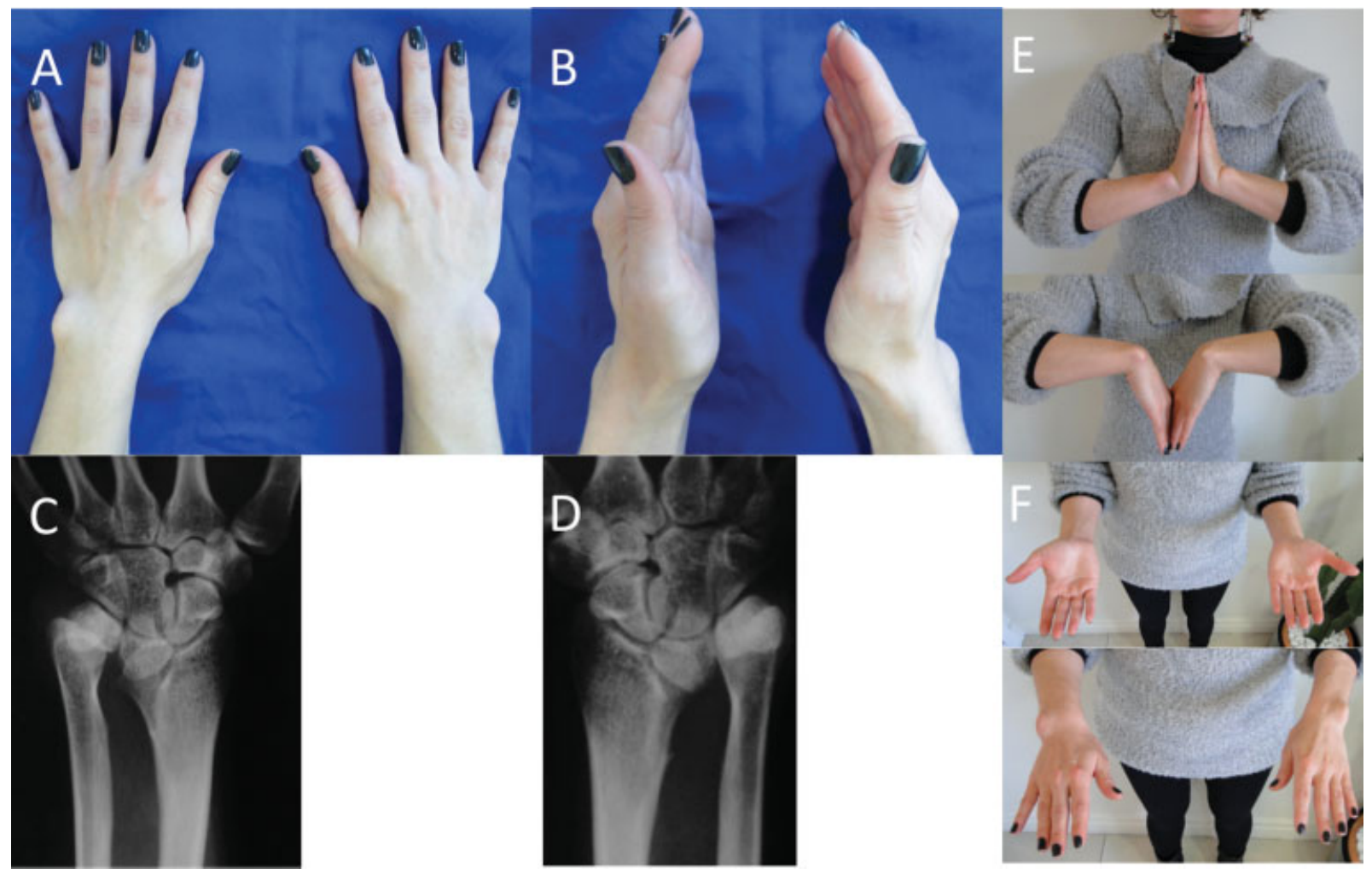

Fig. 6 Female patient, 35 years old, with bilateral MDy, and more than 20 years of clinical follow-up (A,B). The radiographs show MD (C,D). Clinically, the patient shows good range of motion, with slight loss of wrist extension and flexion. Forearm pronation and supination are retained (C).

In adult patients with MD, spontaneous rupture of the extensor tendons of the digits due to attrition with DRUJ irregularities has also been described, a mechanism similar to that of rheumatoid arthritis. ${ }^{30}$

As a general rule, invasive treatment (surgery) should be considered in patients who present such a deformity that is intense enough to bring about symptoms before physeal closure, and in cases of severe deformity causing functional disability and pain. ${ }^{1,5,21}$

\section{Surgical Treatment}

Symptomatic patients or those with cosmetic complaints, with advancing disease and significant progression close to skeletal maturity, often require surgical treatment. Surgery aims to achieve pain relief and functional recovery, with cosmetic issues considered a secondary concern. . $^{1,5,21}$

Treatment should consider the degree of skeletal maturity; the severity of the angular deformities and the lunate fossa; symptom intensity; the degree of chondral compromise; DRUJ instability; the presence of radiocarpal osteoarthritis; and the presence of ulnocarpal impingement syndrome (-Table $\mathbf{1}) \cdot^{13,21}$

The surgical treatment is divided into groups of procedures according to skeletal maturity, the severity of the deformity, and the presence of degenerative changes.

\section{Immature Skeleton with High Growth Potential}

\section{Physiolysis with Resection of the Vickers Ligament (Surgical} Technique)

Vickers' ligament, due to its different from normal metaphyseal insertion of radiocarpal ligaments that have their

Table 1 Treatment of Madelung Deformity Based on Disease Staging. The authors' preferred procedures for each stage are shown in bold.

\begin{tabular}{|l|l|}
\hline Evolutive stage & Procedures \\
\hline $\begin{array}{l}\text { Immature skeleton } \\
\text { with high growth } \\
\text { potential }\end{array}$ & $\begin{array}{l}\text { Resection of the Vickers ligament } \\
\text { Physiolysis } \\
\text { Physiolysis + resection of the } \\
\text { Vickers' ligament }\end{array}$ \\
\hline $\begin{array}{l}\text { Immature skeleton } \\
\text { and low growth } \\
\text { potential }\end{array}$ & $\begin{array}{l}\text { Dome osteotomy of the } \\
\text { radius + physiolysis }\end{array}$ \\
\hline $\begin{array}{l}\text { Mature skeleton } \\
\text { without } \\
\text { degenerative } \\
\text { changes }\end{array}$ & $\begin{array}{l}\text { Ulnar shortening osteotomy } \\
\text { Radius volar opening osteotomy } \\
\text { Radius dorsal closure } \\
\text { osteotomy + ulnar shortening }\end{array}$ \\
\hline $\begin{array}{l}\text { Patients with } \\
\text { degenerative } \\
\text { changes }\end{array}$ & $\begin{array}{l}\text { Darrach procedure } \\
\text { Sauvé-Kapandji procedure } \\
\text { DRUJ arthroplasty }\end{array}$ \\
\hline
\end{tabular}


proximal attachment at the epiphysis, creates physis compression of ulnar and volar radius during growth. Authors in the literature ${ }^{10,13}$ rely on that theory to explain the early physeal closure of distal radius at that region. This ligament would also be responsible for generating the iverted pyramid shape of the carpus by anchoring the lunate at a lower position. ${ }^{10,13}$

The proper procedure at this stage of evolution was described by and has been historically named after Langenskiöld; nonetheless, Vickers was responsible for its popularity in the treatment of $\mathrm{MD}^{4,5,10}$ (-Fig. 4B). The procedure consists of release (closure) of the physeal bar at the volar and ulnar regions of the distal radius, associated to anomalous ligament resection. Some authors in the literature ${ }^{5}$ initially employed a transverse volar approach to the wrist. Later, other authors ${ }^{21}$ favored the longitudinal approach. The radiolunate ligament is elevated from the radius and resected. Next, an osseous portion, $5 \mathrm{~mm}$ from the DRUJ, connecting the metaphysis to the epiphysis and passing through the physis, is osteotomized and resected. For greater precision, perforations with a Kirschner wire may be performed to demarcate a dotted line that indicates the bone to be resected. The interposition of fat is still performed in the bone defect to prevent the formation of a new physeal bone bar. $5,10,21,31$

Despite promising reports ${ }^{13}$ of isolated resection of the Vickers ligament in mild deformities and early stages, there is still no consistent evidence that such isolated procedure is an effective treatment. ${ }^{13}$

\section{Epiphysiodesis of Distal Ulnar Physis}

It is more of a historical procedure, and not commonly used nowadays.

\section{Immature Skeleton with Low Growth Potential}

Radius Dome Osteotomy Associated to Physiolysis (Surgical Technique)

Procedures that address only the progression of deformity in patients with advanced degree of skeletal maturity are deemed insufficient. In this case, corrective surgeries should be performed. ${ }^{11-13,21}$

In 2006, Harley et al. ${ }^{11}$ published good results with the Henry volar approach. Using curved osteotomes, a dome osteotomy is performed in the metaphysis of the distal radius along with the release of the thickened radiocarpal ligaments. After the osteotomy, the distal fragment is aligned through a maneuver that demands traction, radial deviation, pronation, and dorsal translocation. The original technique employs 2.4-mm Steinmann pins for osteotomy fixation, which are retained for 6 weeks ${ }^{11}$ (-Fig. 4C).

\section{Mature Skeleton Without Degenerative Changes}

Isolated Osteotomy of the Radius (Surgical Technique) Isolated Osteotomy recommended to correct primary deformity of the radius. Different forms of radial osteotomies are used, including closing and opening wedges for intra- operative correction, or progressive correction by means of the Ilizarov technique. ${ }^{12,29,32-36}$

Currently, the trend is to prioritize radial opening procedures and thus promote an improvement in ulnar variance, as it enables an increase in radial length, in addition to the correction of the primary defect. ${ }^{12,34,36,37}$ To avoid overlengthening of the radius in one single procedure, some authors advocate the association of this technique to ulnar shortening osteotomy. ${ }^{38,39}$

\section{Isolated Ulnar Osteotomy}

Because most complaints and symptoms are related to dorsal ulnar prominence and ulnocarpal impingement, ulnar shortening procedures can offer considerable clinical improvement. Minimally-invasive-osteotomy devices can now be used, producing an equally-effective and more biological procedure. $^{40,41}$

\section{Patients with Degenerative Changes}

\section{DRUJ Arthroplasty (Surgical Technique)}

Patients with advanced MD whose treatment in earlier stages has been insufficient or delayed may develop severe symptoms from DRUJ instability, severe limitation to pronosupination, and relevant prominence of the distal ulna. The Darrach and Sauvé-Kapandji procedures have been classically described (-Fig. 7). An alternative to those procedures is DRUJ total arthroplasty with a semi-constrained prosthesis, as described by Coffey et al. ${ }^{42}$ This procedure involves the use of a metallic component fixed to the radius, covering the sigmoid fossa, with an ulnar intramedullary stem comprised of a final spheroid structure of ultra-high molecular weight polyethylene replacing the distal ulna. It is of note that patients with serious anatomical changes concomitant to DRUJ compromise may require previous corrective procedures (radial or ulnar osteotomy). ${ }^{42}$

\section{Concepts by Authors in the Literature}

As described by Harness et al. ${ }^{43}$ in 2004, the volar and ulnar portions of the distal radius are the cornerstone for carpal stabilization. In distal radius fractures, the compromise of that site creates severe instability and lunate volar displacement, with ensuing carpal volar subluxation. In MD, the carpus behaves in the same way; however, the literature does not emphasize that the hypoplastic volar and ulnar portions of the radius cause the carpus, and mainly the lunate, to displace volarly.

The anatomical change in the volar radiocarpal ligaments (VRCLs), described by Vickers and Nielsen ${ }^{10}$ as a thick cord directed towards the lunate bone, is suggested as the possible cause of physeal injury at that area of the radius. Nonetheless, to date, it cannot be stated with certainty if the anatomical changes in the VRCLs and the pronator quadratus muscle would be the cause or a consequence of MD. 5,13,21

We consider that, since the Vickers ligament is not present in every patient with MWD, and because the patients in the series reported by Vickers and Nielsen ${ }^{10}$ had a mean age $>12$ 

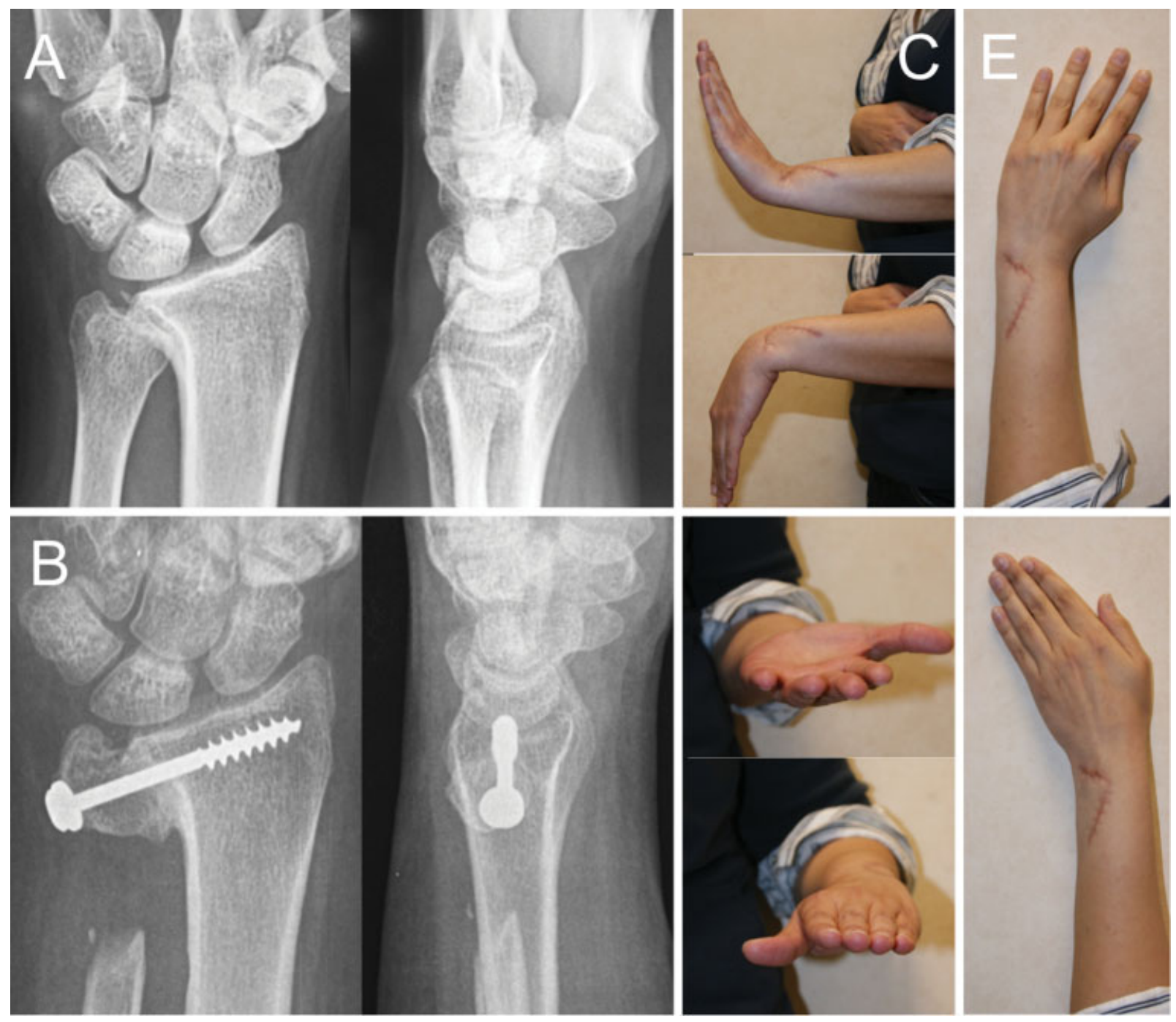

Fig. 7 Female MD patient, 37 years old, complaining of pain (score of 7/10 on the Visual Analog Scale [VAS]), and restriction in pronosupination (total: $\left.50^{\circ}\right)(\mathrm{A})$. The radiographs showed advanced degenerative changes in the DRUJ (B). Sauvé-Kapandji resection arthroplasty was indicated and performed. At 12 months of evolution, the patient presented well-aligned healing at the DRUJ arthrodesis, and considerable pain improvement (VAS score of 2/10), along with good recovery of flexion-extension, pronosupination, and wrist radial and ulnar tilts (B-E).

years - that is, patients in advanced stages of the disease -, VRCL thickening would be an adaptive hypertrophy in an attempt to contain the volar subluxation of the carpus, particularly the lunate. Therefore, resection of the Vickers ligament as an isolated treatment in childhood may not only not help, but might even worsen carpal instability.

Most treatments proposed for MD address the changes in the ulnar side of the wrist. ${ }^{40-42,44}$ Those techniques do not aim at correcting the radial deformity of the volar aspect of the lunate fossa, the site of origin of the disease. There is no description of intra-articular correction of radiocarpal changes, as there is for other changes in the surface of the distal radius joint. ${ }^{45,46}$ The disadvantage of any extra-articular osteotomy of the radius is the fact that improving the joint surface tilt may lead to a "funnel-shaped" carpus in radial deviation, as its triangular shape will not change, and may result in limitation to ulnar deviation and long-term degenerative changes.
Several authors ${ }^{47,48}$ have described good results with the use of volar osteotomy of the distal radius for different changes. In an analogy to hip dysplasia, in which there is a lack of acetabular coverage for the femoral head, we suggest a new treatment method for MD in skeletally-mature patients without degenerative changes. We advocate for a distal radius osteotomy through a volar approach so that joint realignment is achieved to improve the contact area of the lunate bone. The rotation and lengthening of the distal epiphysis of the radius create support and coverage for the lunate bone, improving the alignment of both the radiocarpal joint and the DRUJ.

The initial idea of a simple, obvious procedure with intra-articular osteotomy and bone grafting seems too aggressive to an already diseased carpus, and will certainly lead to joint stiffness and an increase in pain. ${ }^{45,46}$ Therefore, we decided to use the dysplastic distal radius 

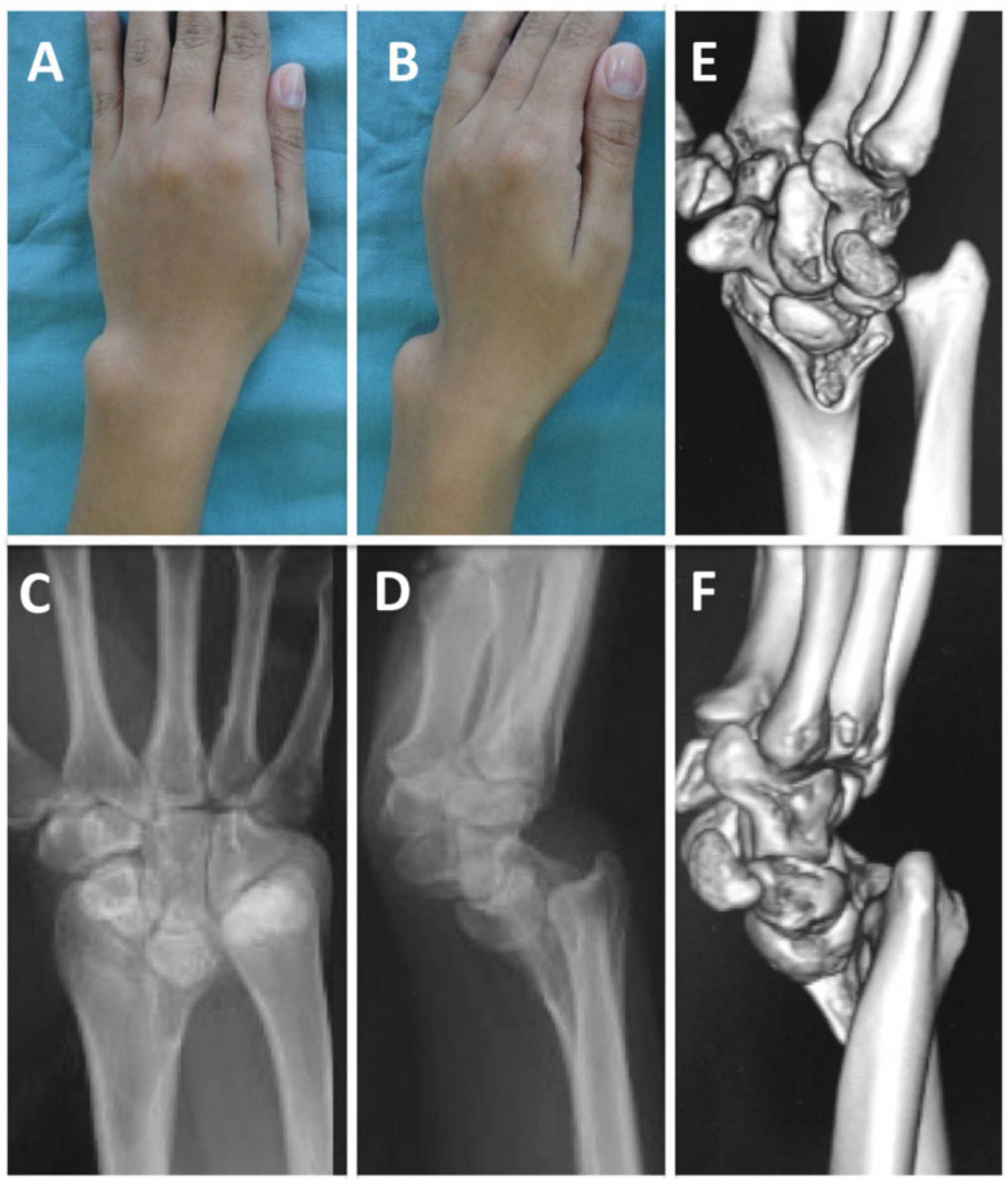

Fig. 8 A 24-year-old female patient with the diagnosis of MD complaining of pain and deformity in the left wrist (A,B). The X-rays showed the typical features of the disease, including distal radius shortening and volar angulation, along with lunate volar subluxation, but no degenerative signs (C,D). Tomographic study with three-dimensional reconstruction images detailing wrist deformity. The anteroposterior view of the joint shows distal radius shortening and increased ulnar angulation (D). The lateral view shows lunate volar subluxation caused by the absence of the volar and ulnar extremities of the distal radius (E). 

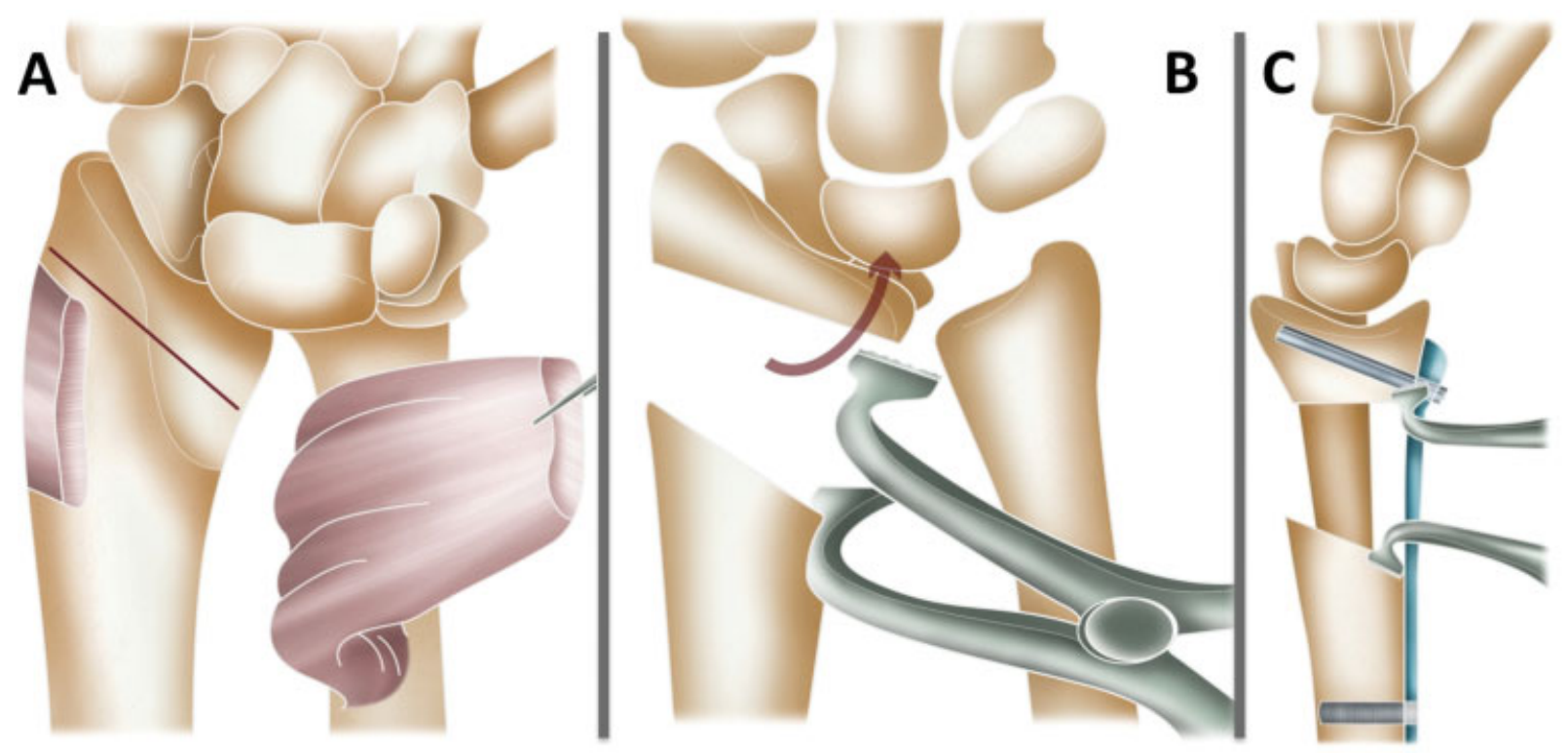

Fig. 9 Schematics of the volar shelf technique of osteotomy for lunate coverage. A volar wrist incision through the flexor carpi radialis is placed with elevation of the pronator quadratus muscle in an L-shaped fashion to reach the volar bone aspect of the distal radius (A). After the osteotomy, the distal epiphysis of the radius is repositioned to increase the coverage area of the lunate and the support (shelf). A laminar spreader is positioned at the most volar and ulnar portions of the radius, to lengthen and rotate the radial distal epiphysis (B). A fixed-angle volar plate is placed for osteotomy fixation after carpal alignment correction (C).
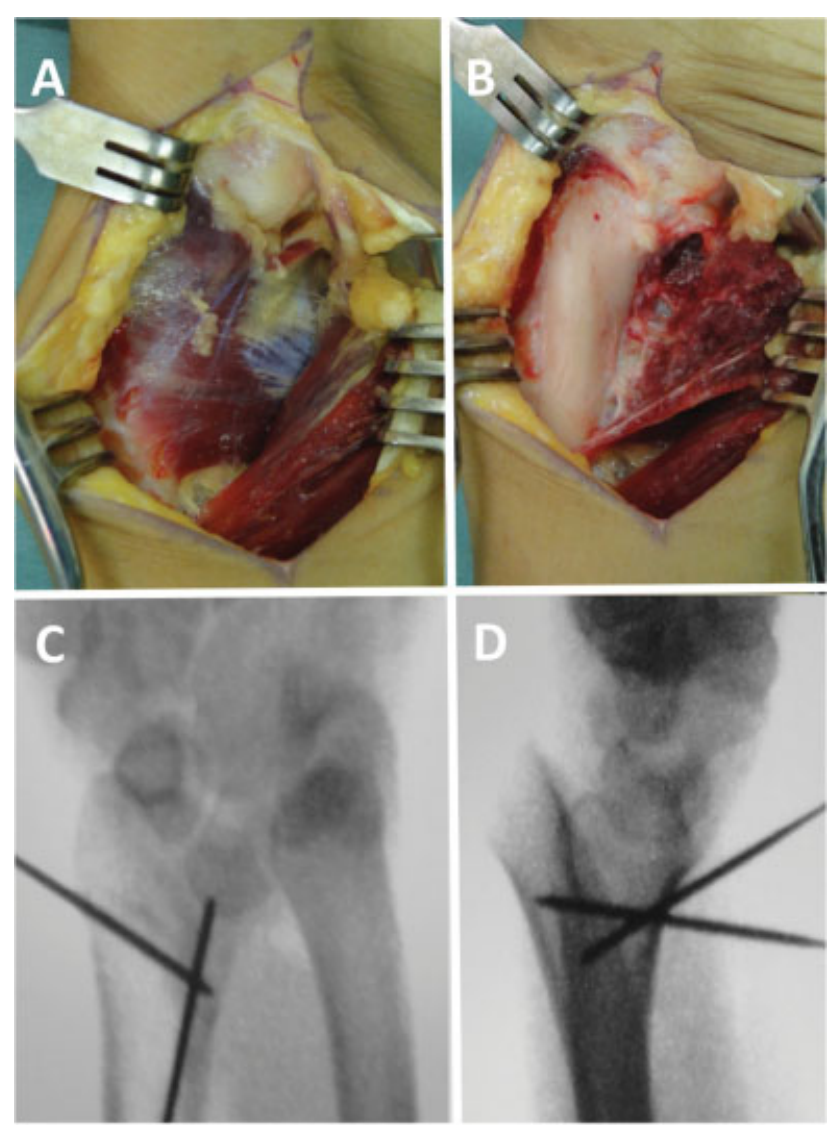

Fig. 10 Intraoperative view of the patient in -Figure 7. Flexor Carpi Radialis (FCR) type extended volar approach (A). Elevation of the pronator quadratus muscle (B).Kirschner wires are used as guides for the osteotomy that is placed $1.5 \mathrm{~cm}$ proximally to the joint and parallel to the articular surface (C,D). itself for joint reconstruction. An adequate coverage and support to the lunate bone is achieved through an extraarticular osteotomy and with the rotation of the epiphysis of the radius (-Figs. 8 and $\mathbf{9}$ ). This is the "shelf" procedure for MD, in an analogy to the well-established technique used for congenital hip dysplasia. The osteotomy is fixated with a locking plate applied to the volar aspect of distal radius.

Hypertrophic and thickened VRCLs can be observed, and, in this technique, they are neither resected nor lengthened. The origin of radiocarpal ligaments at the ulnar portion of the distal radius will likely be the most distal limit of the osteotomy. The distal epiphysis of the radius is repositioned to enable the provision of support and coverage for the lunate bone. The maneuver is performed with a laminar spreader positioned at the extreme volar and ulnar portions of the osteotomy. The tool helps in lengthening and rotation of the distal epiphysis of the radius, which will be greater at this side of the radius ${ }^{39}$ (-Figs. 10 and 11).

In patients in need of little lengthening, radial osteotomy may be performed in isolation. However, when radial shortening is severe (greater than $2 \mathrm{~cm}$ ), we advise to proceed with an ulnar shortening osteotomy (described by Milch), which facilitates the reduction of the distal radioulnar joint and reduces the amount of necessary bone grafting to fill the void created in the radius (-Figs. 12 and 13).

In patients with degenerative radiocarpal and DRUJ changes, Kaempf de Oliveira et al. ${ }^{27}$ have described an intra-articular technique for distal radius reconstruction. It employs the lunate bone to reconstruct the distal radius, 



Fig. 11 After the osteotomy, the distal epiphysis of the radius is repositioned to increase the contact area and coverage (shelf) of the lunate. A laminar spreader is positioned at the most volar and ulnar portions of the radius to lengthen and rotate its distal epiphysis (A,B). A fixed-angle volar plate is used for osteotomy fixation (C).
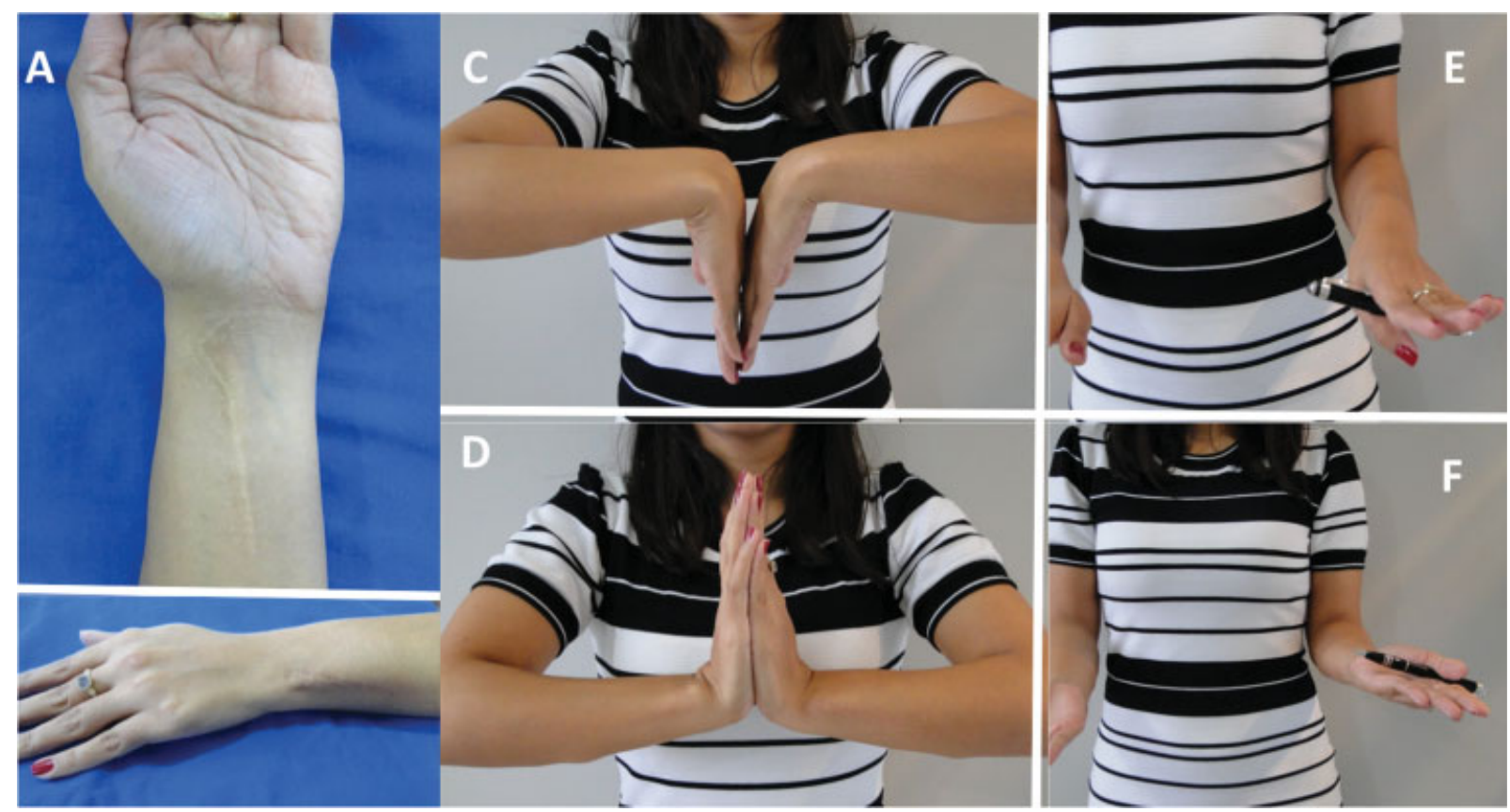

Fig. 12 Clinical aspect of the patient at five years postoperatively. Wrist alignment has improved, and the distal ulnar protrusion is no longer visible $(\mathrm{A}, \mathrm{B})$. Final range of motion of $85^{\circ}$ of flexion (C); $80^{\circ}$ of extension (D); $90^{\circ}$ of supination (E); and $90^{\circ}$ of pronation (F). 

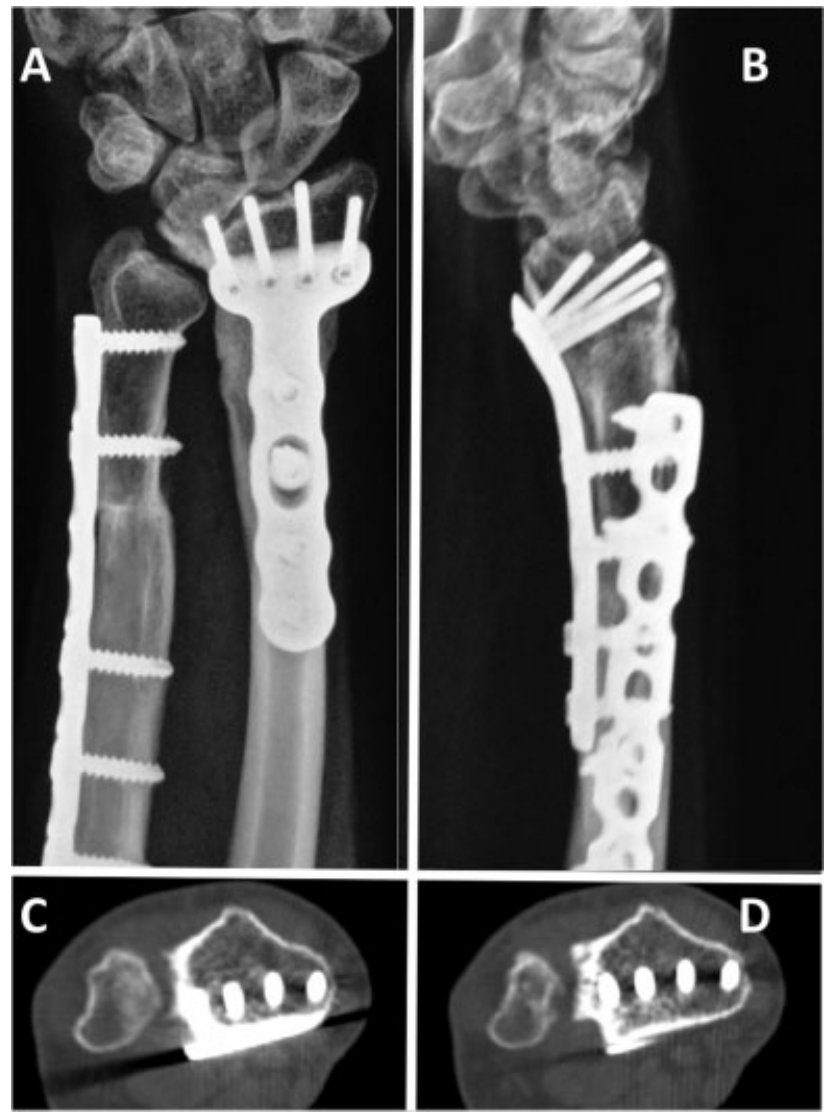

Fig. 13 Five years after the shelf osteotomy, the X-rays show complete bone healing and remodeling at the site of the procedure. There are no RCJ or DRUJ degenerative changes. Wrist alignment has been corrected with improved lunate volar subluxation $(A, B)$. Tomographic slices showing plate positioning and its relation to the DRUJ (C,D).

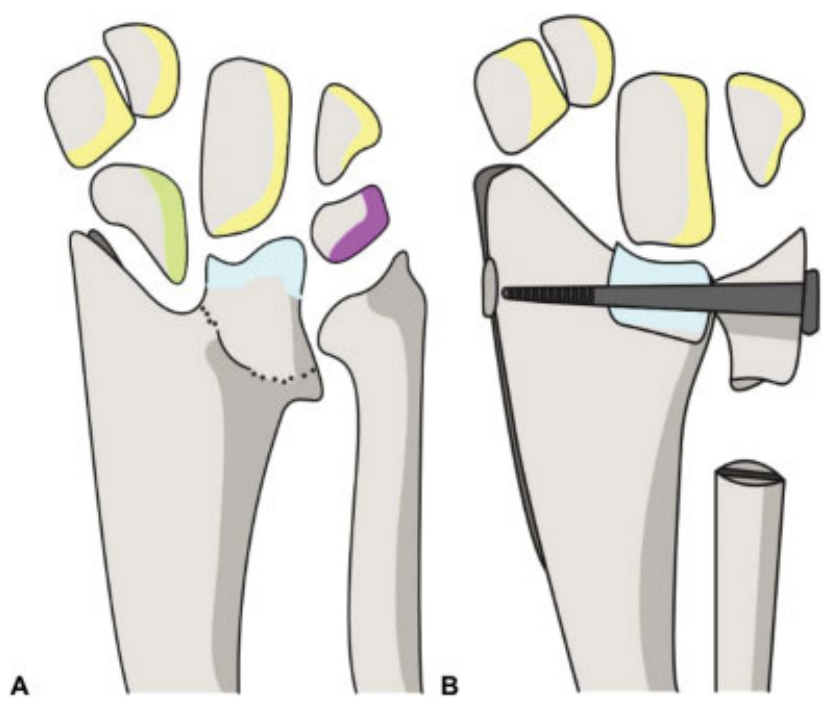

Fig. 15 Illustrative figure made from the anteroposterior radiograph of the wrist. Scaphoid in green; lunate in blue; triquetrum in pink; and second carpal row in yellow (A). Preoperative planning with proximal row carpectomy; Sauvé-Kapandji procedure at the DRUJ; and reconstruction of the dysplasia of the volar portion of the lunate fossa along with the lunate bone. The lunate graft in the radius is in blue (B).

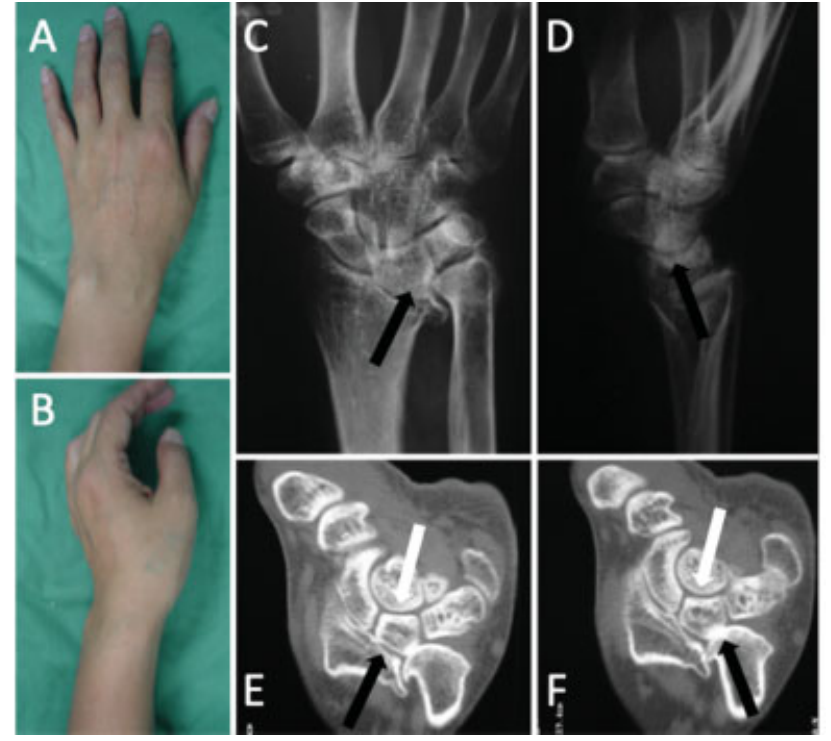

Fig. 14 40-year-old female secretary with bilateral MD, with complaints of bilateral pain and deformity in both wrists for more than 25 years $(A, B)$. Anteroposterior $(C)$ and lateral $(D)$ radiographs revealing severe degeneration of the distal radioulnar joint and between the radius and lunate fossa (black arrows). Computed tomography (E F) ascertains the severe degeneration (black arrows), showing the preservation of joint line between the distal lunate and proximal capitate bones (white arrows).

associated with proximal carpectomy and the SauvéKapandji procedure. The technique is performed through a dorsal longitudinal incision, followed by a dorsally-based, Vshaped radiocarpal capsulotomy. The Sauvé-Kapandji procedure is performed through the same dorsal incision; lunate positioning and fixation are performed at the void created in the distal radius. The resected portion of the ulnar neck is employed as a bone graft for the radius. Definitive fixation of the ulnar distal portion and lunate grafting are performed with a $4.5-\mathrm{mm}$ cannulated screw with a washer, associated to a Kirschner wire to avoid fragment rotation (-Figs. 14 and 15).

The procedure promotes an improvement in pain, grip strength, and pronosupination, with no considerable change in the radiocarpal ROM. As observed in patients submitted to proximal carpectomy, our technique does not offer complete recovery of wrist motion; however, it does not cause either a significant impairment of function or the need for a revision surgery $^{27}$ (-Figs. 16 and 17).

Another possible treatment option for adult or elderly patients with MD associated to degenerative changes is selective carpal denervation, which provides a reduction of pain while preserving the motion of the wrist joint. ${ }^{49}$

The association of MD with distal radius fracture is exceedingly rare. There are only two articles ${ }^{50,51}$ in the literature about that association. The first one ${ }^{50}$ describes an extra-articular fracture treated conservatively; and 

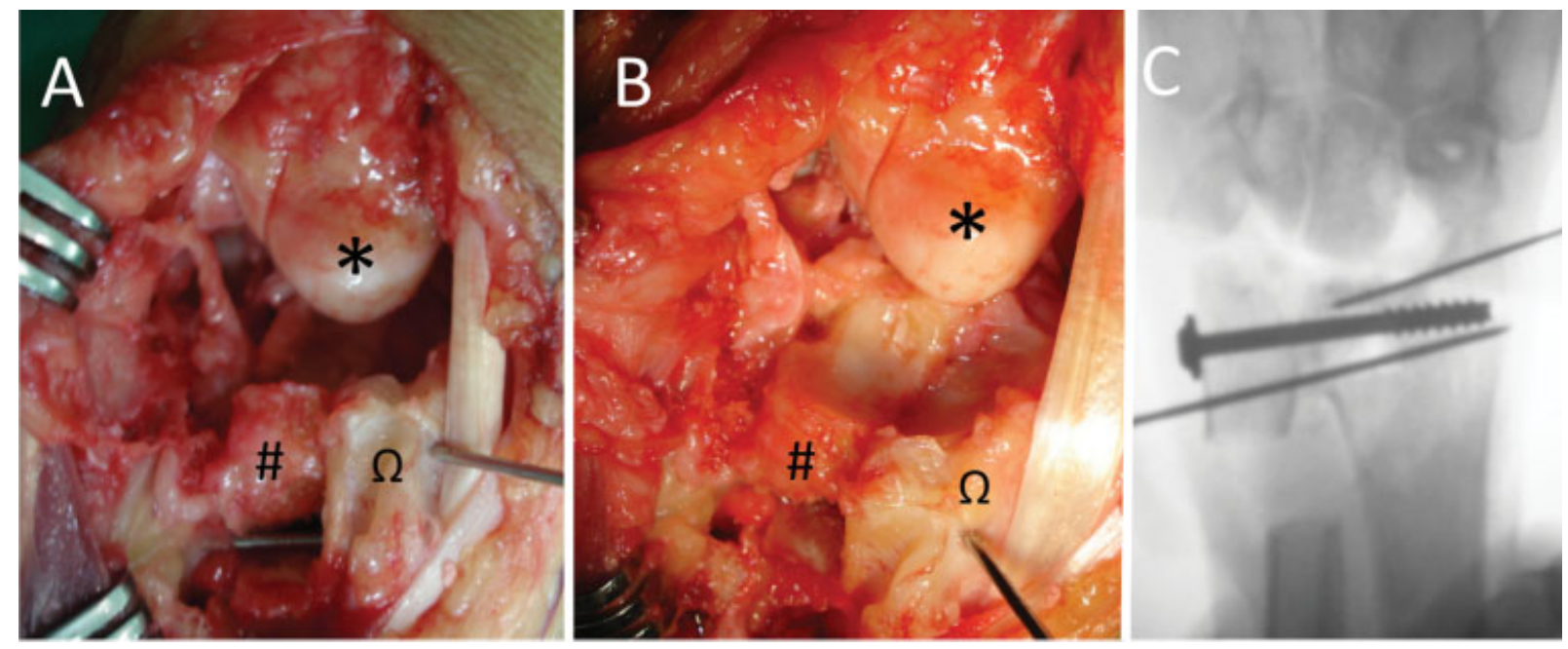

Fig. 16 Intraoperative view. Good quality of the proximal capitate portion of the joint $\left(^{*}\right)$ and distal radius lunate fossa $(\Omega)$, employing the lunate bone as a graft for the reconstruction of the distal radius lunate fossa (\#) (A). Good congruity between the radius $(\Omega)$, lunate graft (\#), and capitate proximal pole $\left({ }^{*}\right)(B)$.

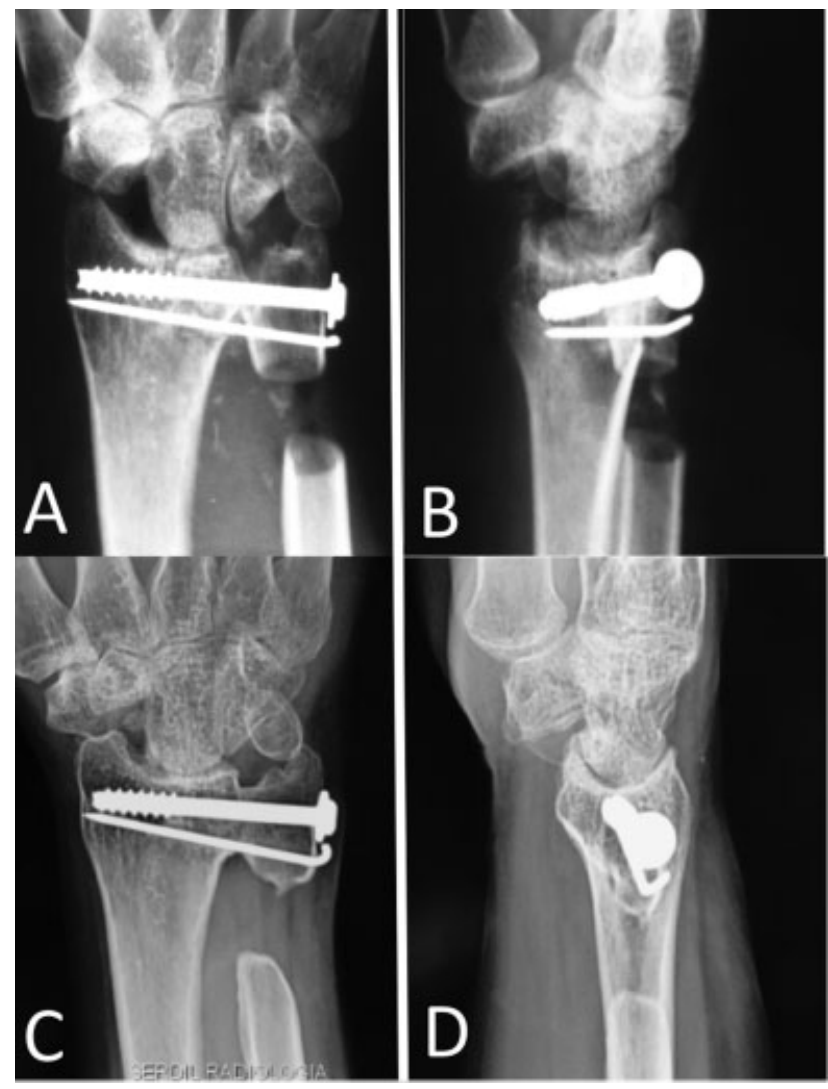

Fig. 17 Early postoperative anteroposterior (A) and lateral (B) radiographs. Good radiocarpal alignment is observed, along with correction of the deformity. Radiographs after ten years of evolution (C,D). Healing of the DRUJ and lunate graft arthrodesis. The joint space between the lunate fossa and the capitate has also been preserved, albeit with a moderate degenerative process. Clinical appearance at ten years of evolution. Patient has reasonable range of motion, with neither pain nor deformity $(\mathrm{E}, \mathrm{F})$. the second one ${ }^{51}$ reports the onset of MD after a distal radius fracture. We have operated our first patient with an intraarticular fracture of the distal radius with MD using a locked volar plate, and we have obtained an excellent functional outcome (-Fig. 18).

\section{Conclusion}

In recent years, diagnostic radiologic criteria have greatly evolved in a more standardized and clearer fashion. There is still no rule of thumb to define the ideal treatment for patients with MD. The results with the early treatment by physiolysis seem promising. However, it is still difficult to advocate surgical treatment for patients with mild deformity and few symptoms, as there is no way to know which ones will be symptomatic in the future. With time, we will probably not treat patients with MD, but rather patients at risk of developing the disease.

The advancement in imaging modalities (CT and MRI) and the improvement in fixation materials have greatly helped to improve the results of corrective osteotomies in patients bearing the deformity. The clearer and more precise visualization of the deformity, including tridimensional reconstructions, enables a better planning and execution of the procedure.

In the present article, we provide an overview of MD history, as well as the classical treatment and management of this pathology. It is important to stress that we are evolving, but there is still much to discover regarding MD.

Conflict of Interest

The authors have no conflict of interests to disclose. 

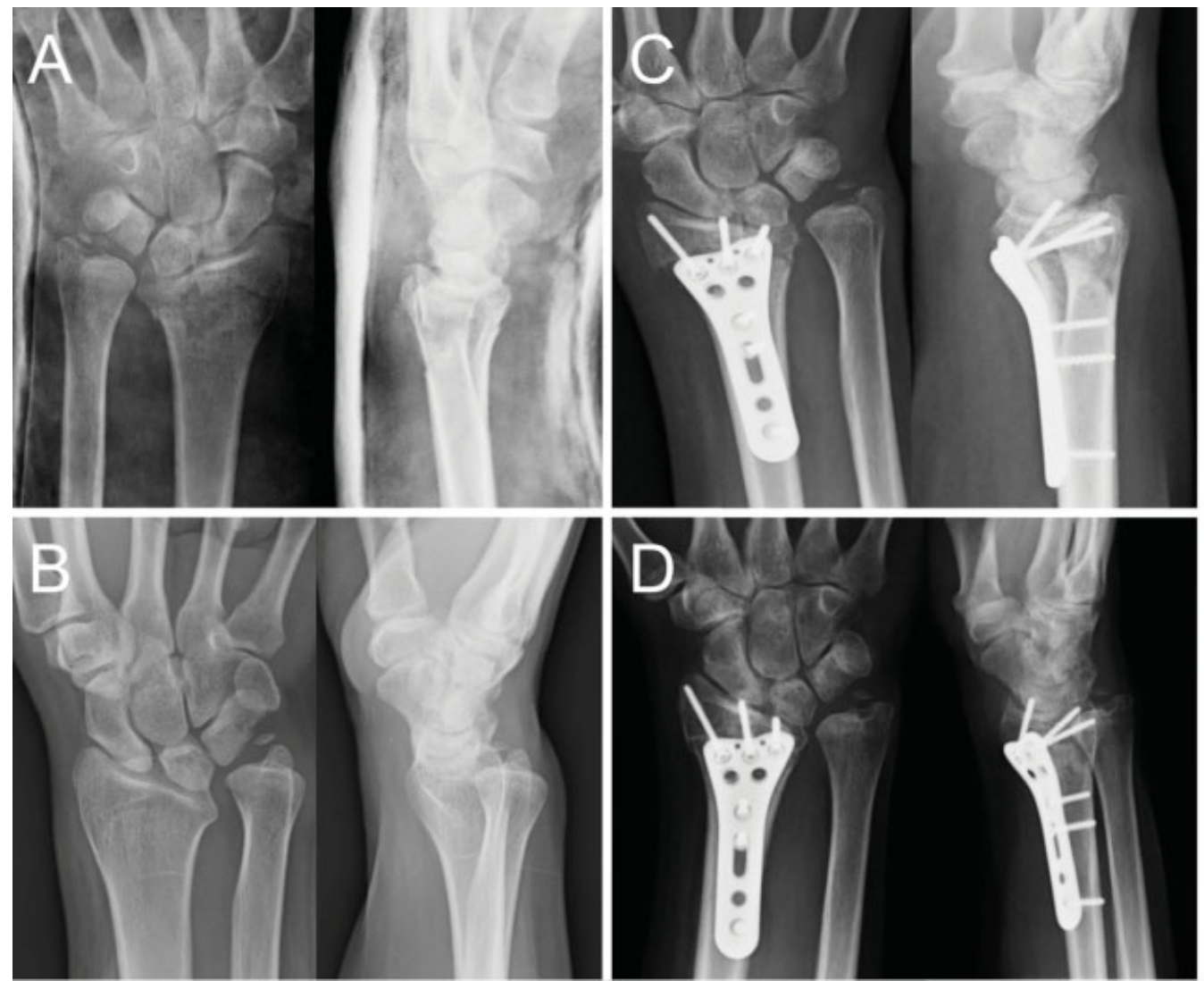
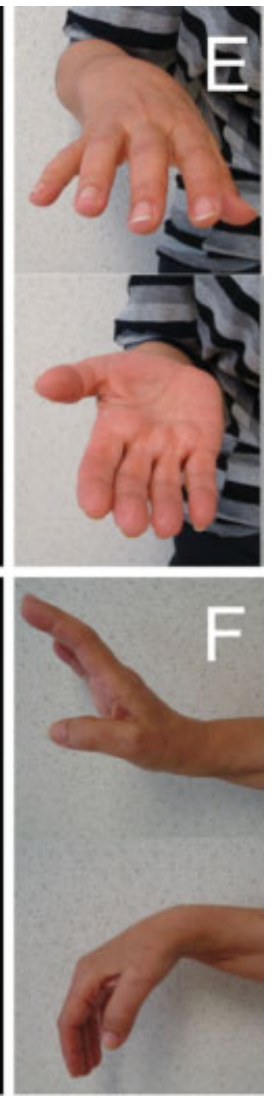

Fig. 18 56-year-old female patient with bilateral MWD who sustained a domestic fall to the ground with trauma to the right wrist. The radiographs showed a displaced intra-articular fracture of the right distal radius $(A, B)$. The surgical treatment through open reduction and internal fixation with a locked volar plate. During the procedure, attention was paid to the reduction and improvement in the alignment of the radiocarpal joint and the DRUJ. Radiographs at 30 days and at 12 months of evolution, showing reduction maintenance and fracture healing (C, D). At 12 months postoperatively, the patient presented good clinical evolution, with recovery of flexion-extension and pronosupination (E,F).

\section{References}

1 Ghatan AC, Hanel DP. Madelung deformity. J Am Acad Orthop Surg 2013;21(06):372-382. Doi: 10.5435/JAAOS-21-06-372

2 Arora AS, Chung KC. Madelung and the recognition of Madelung's deformity. J Hand Surg Am 2006;31(02):177-182

3 Peymani A, Johnson AR, Dowlatshahi AS, et al. Surgical Management of Madelung Deformity: A Systematic Review. Hand (N Y) 2019;14(06):725-734. Doi: 10.1177/1558944718793179

4 Knutsen EJ, Goldfarb CA. Madelung's Deformity. Hand (N Y) 2014; 9(03):289-291. Doi: 10.1007/s11552-014-9633-y

5 Babu S, Turner J, Seewoonarain S, Chougule S. Madelung's Deformity of the Wrist-Current Concepts and Future Directions. J Wrist Surg 2019;8(03):176-179. Doi: 10.1055/s-0039-1685488

6 Madelung O. Die spontane subluxation de hand nachvorne. Verhandlungen der Deutschen Gesellschaft für Chirurgie. 1950. ISBN: 978-3-662-22828-9

7 Zebala LP, Manske PR, Goldfarb CA. Madelung's deformity: a spectrum of presentation. J Hand Surg Am 2007;32(09): 1393-1401

8 Nielsen JB. Madelung's deformity.A follow-up study of 26 cases and a review of the literature. Acta Orthop Scand 1977;48(04): 379-384

9 Sellami M, Maatallah K, Riahi H, Bouaziz MC, Hamdi W, Kchir MM. Madelung Deformity. J Clin Rheumatol 2020;26(08):e317-e318. Doi: 10.1097/RHU.0000000000001172

10 Vickers D, Nielsen G. Madelung deformity: surgical prophylaxis (physiolysis) during the late growth period by resection of the dyschondrosteosis lesion. J Hand Surg [Br] 1992;17(04):401-407. Doi: 10.1016/s0266-7681(05)80262-1

11 Harley BJ, Brown C, Cummings K, Carter PR, Ezaki M. Volar ligament release and distal radius dome osteotomy for correction of Madelung's deformity. J Hand Surg Am 2006;31(09):1499-1506

12 Harley BJ, Carter PR, Ezaki M. Volar surgical correction of Madelung's deformity. Tech Hand Up Extrem Surg 2002;6(01):30-35. Doi: 10.1097/00130911-200203000-00006

13 Carter PR, Ezaki M. Madelung's deformity. Surgical correction through the anterior approach. Hand Clin 2000;16(04):713-721, $\mathrm{x}-\mathrm{xi}$

14 Burgos L, Walker M, Daley RA. A Variant of Madelung Deformity: Management of the Distal Ulna Within the Carpal Canal. J Hand Surg Am 2021;46(05):429.e1-429.e6. Doi: 10.1016/j. jhsa.2020.06.007

15 Benito-Sanz S, Thomas NS, Huber C, et al. A novel class of Pseudoautosomal region 1 deletions downstream of SHOX is associated with Leri-Weill dyschondrosteosis. Am J Hum Genet 2005;77(04):533-544

16 McCarroll HR Jr, James MA, Newmeyer WL III, Molitor F, Manske PR. Madelung's deformity: quantitative assessment of $x$-ray deformity. J Hand Surg Am 2005;30(06):1211-1220. Doi: 10.1016/j. jhsa.2005.06.024

17 McCarroll HR Jr, James MA, Newmeyer WL III, Manske PR. Madelung's deformity: diagnostic thresholds of radiographic measurements. J Hand Surg Am 2010;35(05):807-812. Doi: 10.1016/j.jhsa.2010.02.003 
18 Peymani A, Dobbe JGG, Streekstra GJ, McCarroll HR, Strackee SD. Quantitative three-dimensional assessment of Madelung deformity. J Hand Surg Eur Vol 2019;44(10):1041-1048. Doi: $10.1177 / 1753193419876203$

19 Hegazy G, Mansour T, Alshal E, Abdelaziz M, Alnahas M, El-Sebaey I. Madelung's deformity: capitate-related versus ulna-related measurement methods. J Hand Surg Eur Vol 2019;44(05): 524-531. Doi: $10.1177 / 1753193419832233$

20 Farr S, Guitton TG, Ring DScience of Variation Group. How Reliable is the Radiographic Diagnosis of Mild Madelung Deformity? . J Wrist Surg 2018;7(03):227-231. Doi: 10.1055/s-0037-1612636

21 Kozin SH, Zlotolow DA. Madelung Deformity. J Hand Surg Am 2015;40(10):2090-2098. Doi: 10.1016/j.jhsa.2015.03.033

22 Cook PA, Yu JS, Wiand W, et al. Madelung deformity in skeletally immature patients: morphologic assessment using radiography, CT, and MRI. J Comput Assist Tomogr 1996;20(04):505-511

23 Hanson TJ, Murthy NS, Shin AY, Kakar S, Collins MS. MRI appearance of the anomalous volar radiotriquetral ligament in true Madelung deformity. Skeletal Radiol 2019;48(06):915-918. Doi: 10.1007/s00256-018-3094-2

24 Stehling C, Langer M, Nassenstein I, Bachmann R, Heindel W, Vieth V. High resolution 3.0 Tesla MR imaging findings in patients with bilateral Madelung's deformity. Surg Radiol Anat 2009;31(07): 551-557

25 Ogino T, Ishigaki D, Satake H, Iba K. Free fat graft for congenital hand differences. Clin Orthop Surg 2012;4(01):45-57. Doi: 10.4055/cios.2012.4.1.45

26 Otte JE, Popp JE, Samora JB. Treatment of Madelung Deformity WithVicker Ligament Release and Radial Physiolyses: A Case Series. J Hand Surg Am 2019;44(02):158.e1-158.e9. Doi: 10.1016/j.jhsa.2018.04.033

27 Kaempf de Oliveira R, Delgado PJ, Ribak S, Bertelli JA, da Silva Marques F. Lunate Grafting Into the Radius for Lunate Fossa Reconstruction in Madelung Deformity. J Hand Surg Am 2018; 43(07):683.e1-683.e5. Doi: 10.1016/j.jhsa.2018.01.014

28 Yanagisawa S, Takagi T, Murase T, Kobayashi Y, Watanabe M. Open Wedge Osteotomy with Ulnar Shortening for Madelung Deformity Using a Computer-Generated Template. J Hand Surg Asian Pac Vol 2017;22(04):538-543. Doi: 10.1142/S021881041772042X

29 Imai Y, Miyake J, Okada K, Murase T, Yoshikawa H, Moritomo H. Cylindrical corrective osteotomy for Madelung deformity using a computer simulation: case report. J Hand Surg Am 2013;38(10): 1925-1932. Doi: 10.1016/j.jhsa.2013.07.006

30 Jebson PJ, Blair WF. Bilateral spontaneous extensor tendon ruptures in Madelung's deformity. J Hand Surg Am 1992;17(02): 277-280. Doi: 10.1016/0363-5023(92)90405-e

31 Del Core M, Beckwith T, Phillips L, Ezaki M, Stutz C, Oishi SN. Longterm Outcomes Following Vickers Ligament Release and Growth Modulation for the Treatment of Madelung Deformity. J Pediatr Orthop 2020;40(04):e306-e311. Doi: 10.1097/BPO.00000000 00001504

32 Steinman S, Oishi S, Mills J, Bush P, Wheeler L, Ezaki M. Volar ligament release and distal radial dome osteotomy for the correction of Madelung deformity: long-term follow-up. J Bone Joint Surg Am 2013;95(13):1198-1204

33 Megremis P, Megremis O. Bilateral Madelung Wrist Deformity in a 13-Year-Old Girl: Surgical Correction With the Taylor Spatial Frame External Fixation System.J Am Acad Orthop Surg Glob Res Rev 2019; 3(11):e18.00036. Doi: 10.5435/JAAOSGlobal-D-18-00036

34 Van Demark RE Sr, Van Demark RE Jr. Long-term results after the surgical treatment of Madelung's deformity: a case report. J Hand
Surg Am 1993;18(06):1008-1011. Doi: 10.1016/0363-5023(93) 90392-G

35 McCarroll HR Jr, James MA. Very distal radial osteotomy for Madelung's deformity. Tech Hand Up Extrem Surg 2010;14(02): 85-93. Doi: 10.1097/BTH.0b013e3181dba5fe

36 Murphy MS, Linscheid RL, Dobyns JH, Peterson HA. Radial opening wedge osteotomy in Madelung's deformity. J Hand Surg Am 1996; 21(06):1035-1044. Doi: 10.1016/S0363-5023(96)80312-1

37 de Paula EJ, Cho AB, Mattar R Junior, Zumiotti AV. Madelung's deformity: treatment with radial osteotomy and insertion of a trapezoidal wedge. J Hand Surg Am 2006;31(07):1206-1213. Doi: 10.1016/j.jhsa.2006.06.017

38 Laffosse JM, Abid A, Accadbled F, Knör G, Sales de Gauzy J, Cahuzac JP. Surgical correction of Madelung's deformity by combined corrective radioulnar osteotomy: 14 cases with four-year minimum follow-up. Int Orthop 2009;33(06):1655-1661. Doi: 10.1007/s00264-008-0711-z

39 dos Reis FB, Katchburian MV, Faloppa F, Albertoni WM, Laredo Filho J Jr. Osteotomy of the radius and ulna for the Madelung deformity. J Bone Joint Surg Br 1998;80(05):817-824

40 Glard Y, Gay A, Launay F, Guinard D, Legré R Isolated wedge osteotomy of the ulna for mild Madelung's deformity. J Hand Surg Am 2007;32(07):1037-1042. Doi: 10.1016/j.jhsa.2007.05.015

41 Bruno RJ, Blank JE, Ruby LK, Cassidy C, Cohen G, Bergfield TG. Treatment of Madelung's deformity in adults by ulna reduction osteotomy. J Hand Surg Am 2003;28(03):421-426. Doi: 10.1053/ jhsu.2003.50073

42 Coffey MJ, Scheker LR, Thirkannad SM. Total distal radioulnar joint arthroplasty in adults with symptomatic Madelung's deformity. Hand (N Y) 2009;4(04):427-431. Doi: 10.1007/s11552-0099182-y

43 Harness NG, Jupiter JB, Orbay JL, Raskin KB, Fernandez DL. Loss of fixation of the volar lunate facet fragment in fractures of the distal part of the radius. J Bone Joint Surg Am 2004;86(09):1900-1908. Doi: 10.2106/00004623-200409000-00007

44 Angelini LC, Leite VM, Faloppa F. Surgical treatment of Madelung disease by the Sauvé-Kapandji technique. Ann Chir Main Memb Super 1996;15(04):257-264. Doi: 10.1016/s0753-9053(96) 80035-4

45 del Piñal F, Klausmeyer M, Moraleda E, et al. Vascularized graft from the metatarsal base for reconstructing major osteochondral distal radius defects. J Hand Surg Am 2013;38(10):1883-1895

46 Obert L, Lepage D, Sergent P, et al. Post-traumatic malunion of the distal radius treated with autologous costal cartilage graft: a technical note on seven cases. Orthop Traumatol Surg Res 2011; 97(04):430-437

47 Kaempf de Oliveira R, Serrano PJ, Badia A, Ferreira MT. Corrective osteotomy after damage of the distal radial physis in children: surgical technique and results. Tech Hand Up Extrem Surg 2011; 15(04):236-242. Doi: 10.1097/BTH.0b013e31821da4b5

48 de Oliveira RK, Binz MA, Ferreira MT, Ruschel PH, Serrano PD, Praetzel RP. Osteotomy of the distal radius using a fixed-angle volar plate. Rev Bras Ortop 2015;47(02):173-185

49 Pilny J, Slodicka R, Hajek P, Horackova K. Selective Carpus Denervation - One of Treatment Options of Madelung Deformity. Z OrthopUnfall 2020;158(05):497-500. Doi: 10.1055/a-0977-3657

50 Dickson JK, Williams D, Standley D. Traumatic injury to a wrist with incidental Madelung's deformity. Orthop Traumatol Surg Res 2010;96(03):323-324

51 Field JS, Rizzo M. Madelung deformity with prior distal radius fracture: a case report. Am J Orthop 2007;36(06):E91-E93 